\title{
La imagen española del ejército Otomano (1784-1907)
}

\author{
Pablo Martín Asuero
}

\begin{abstract}
RESUMEN ABSTRACT
Con las paces hispano-turcas de finales del siglo XVIII se acaba con la rivalidad de estas dos naciones en el Mediterráneo. A lo largo de la Cuestión

de Oriente militares, diplomáticos, corresponsales de guerra y periodistas iran dando noticias de los cambios producidos en los ejércitos otomanos.

PALABRAS CLAVE
Imperio Otomano, Cuestión de Oriente, ejercito, jenizaros, marina, modernización, Tanzimat, guerra de Crimea, guerra ruso turca 1877-78, Antonio de Zayas, Vicente Blasco lbáñez.

At the end of the 18the century the Spanish-turkish rivalry in the Mediterranean is over. All through the Eastern Question soldiers, diplomats, war reporters and journalist will give notices of the changes in the ottoman army.

KEY WORDS

Ottoman Empire, Eastern Question, army, janissaries, navy, renovation, Tanzimat, Crimean war,

Ruso-turkish war of 1877-78, Antonio de Zayas, Vicente Blasco lbáñez.
\end{abstract}

El tema del presente artículo es uno de los más importantes en la mayoría de los textos que tratan sobre los turcos. No hay que olvidar que las tropas de este pueblo, llegado desde las estepas de Asia Central, acabaron con el Imperio Bizantino al conquistar Constantinopla y dominaron, entre otros territorios, los Balcanes, el norte de Africa y la península Arábiga. Los asedios de Viena y la batalla de Lepanto son, a modo de ejemplo, dos acontecimientos fundamentales a la hora de entender la situación política 
internacional durante la Edad Moderna. A finales del siglo XVIII la hostilidad hispano-turca acaba al firmarse las paces entre estas dos potencias, iniciándose así una nueva fase de acercamiento y entendimiento. Tras el acuerdo alcanzado por Floridablanca y Carlos III, quien había logrado firmar las paces entre Nápoles y Turquía durante su estancia como rey de esta parte de Italia, se envío a Estambul una expedición dirigida por Aristizábal cuya memoria, Viaje a Constantinopla en el año 1784, vería la luz seis años más tarde y puede ser considerada como un compendio del saber de la época sobre el Imperio Otomano. El ejército ocupa un lugar destacado en este texto dedicándole el capítulo XI: Constitución militar. Cuerpos veteranos y colectivos. Sus distinciones y fueros. Cuerpos facultativos. Uno de los componentes que más atención recibe son los jenízaros, responsables de gran parte de las victorias de épocas anteriores. Si bien estas tropas mantienen su papel en la sociedad otomana, han dejado de ser los ejércitos de antaño. José Moreno realiza una breve historia del origen de este tipo de soldados y describe el sistema del devsirme, en el cual jóvenes no musulmanes eran apresados y obligados a seguir una instrucción militar. De esta manera, al no contar con vínculos con los señores feudales, la monarquía otomana se hacía con unos fieles servidores. Durante la visita de la expedición española eran, según José Moreno, 196 compañías compuestas cada una de 271 hombres, es decir, poco más de cincuenta mil soldados acuartelados en las principales ciudades del imperio. A estos había que añadir unos cuatrocientos mil más en las provincias fronterizas europeas, especialmente en las vecinas con Rusia. Una vez descrita la infantería Moreno trata de la caballería otomana que contaba con los famosos caballos de Moldavia, dotados de una resistencia que califica de increíble. El origen centroasiático de los turcos y su supuesta relación con los escitas crea una imagen casi mítica de los jinetes otomanos, junto con la de los destacamentos formados por tártaros auxiliares y los timariotas, procedentes de la nobleza feudal. Otro elemento fundamental en esta clase de textos es la artilleria, un cuerpo en pleno desarrollo durante las últimas décadas del siglo XVIII. Moreno señala la presencia de varios instructores europeos como el Barón de Tott, el conde de Bonneval y el caballero Campbell que aportaron los adelantos tecnológicos de sus naciones en este campo.

La marina otomana aparece en el capítulo XII; aunque desde la derrota de Çesme de 1770 no había conseguido recuperarse de la agresión rusa. En este contexto señala cómo el barón de Tott había dedicado gran parte de sus esfuerzos en poner al día la armada otomana, creando los astilleros de Gálata de Estambul. De esta manera logró desplazar en las artes de la navegación a los griegos, apoyados por los rusos, en beneficio 
de los franceses. Moreno señala que en 1784 construían saetas y barcas cañoneras similares a las españolas y una escasa flota: "Sus fuerzas consistían en veinte y dos navíos (incluso los de dos baterías); de ellos uno sólo era de setenta cañones, y los demás de cincuenta a sesenta. Sus fragatas, desde corbetas hasta las que llevan cuarenta cañones, son catorce. Sus javeques son diez; y sus galeras otras tantas o alguna menos" 1 . No incluye los buques de la marina imperial, ni los guardacostas, ni las marinas de las regencias berberiscas de Argel, Trípoli o Túnez, prácticamente independientes de la metrópoli al final del siglo XVIII.

Un militar español que viajó dos veces a Estambul es el capitán de corbeta José Solano Ortiz de Rozas en 1786 y 1787. Al igual que Moreno dedica un capítulo al ejército y otro a la marina. Esta descripción es más detallada que la de su predecesor, especialmente en la indumentaria de los jenízaros: "Su uniforme de ceremonia es el Benisli, especie de Balandrán corto, un chaleco que dexa ver el pecho, un calzón azul ancho, la babucha roxa, y en la cabeza un casquete blanco de fieltro, en cuyo frente hay una cuchara de metal dentro de una caxa de lo mismo, y pendiente del casquete, sobre la espalda un pedazo quadrilongo de fieltro" ${ }^{2}$. Tanto Moreno como Solano coinciden en afirmar que el ejército otomano ya no es lo que era, siendo la opinión del segundo bastante representativa del estado de la infantería turca:

Pero al mismo tiempo que la continua deserción, a que por carecer de código militar no hay pena señalada, y el mal régimen en el acopio de viveres, y poco cuidado en su calidad y conservación, aminoran y llenan de enfermedades sus exércitos en campaña: la insubordinación a unos Xefes, a cuyo inmediato mando no están acostumbrados, y sus resistencia a sujetarse a las reglas que para las operaciones prescribe el arte Militar, fiando el exito a un irrevocable destino, les quita toda la fuerza que en la acción pudieran tener, y que pierden quando sus enemigos oponen el buen orden, unión y concertadas operaciones a los esfuerzos de una desordenada muchedumbre ${ }^{3}$.

Los jenízaros habian dejado de ser los temibles guerreros que aterrorizaban a los pueblos centroeuropeos y era necesario la implantación de un ejército moderno, similar al de las potencias de europa occidental. Selim III (1789-1807) intentó que las reformas en la armada de su antecesor se produjeran en la infantería, creando en 1794 el nizam-i cedíd, un

\footnotetext{
Moreno, J., Viaje a Constantinopla en el año 1784, Madrid, 1790, pág. 300.

Solano ORtiz de RozAS, Idea del imperio Otomano..., Madrid, Imprenta de Sacha, 1793 pág. 148

3 lb. pág. 151.
} 
cuerpo instruido por oficiales franceses, alemanes e ingleses, dotado de medios financieros propios y con soldados reclutados en Anatolia. Tres años más tarde contaba con 9.200 hombres y 27 oficiales que en 1806 se elevarían a 22.685 soldados y 1.590 oficiales ${ }^{4}$. Los todavía poderosos jenízaros no permitieron que se les desplazara del poder y exigieron la disolución de este nuevo cuerpo. No contentos con deponer a Selim III le ajusticiaron junto con los principales oficiales del nizam-i cedîd, sentando en el trono a su sobrino, Mustafa IV. Domingo Badia y Leblich, también conocido como Ali Bey, visitó Estambul entonces, aportando un interesante comentario sobre este suceso: "siendo como eran (los jenízaros), y lo son aún, los verdaderos déspotas del imperio, se alborotaron y, sacrificaron a la conservación de su poder las cabezas tal vez más útiles al imperio, y destronaron al infeliz Selim III: triunfo deplorable de la anarquía militar que ha hecho retroceder dos siglos la civilización de los turcos" "5.

La llegada de Ali Bey a la capital otomano coincidía con uno de los momentos más confusos de la historia turca contemporánea en la cual los victoriosos guerreros se habían hecho con el control de la ciudad. Así lo afirmaba este observador español: "Causa esto tan extraña mezcla y confusión que el ejército turco no se diferencia, en el fondo, de una reunión de hordas salvajes" ${ }^{6}$.

Los jenízaros se mantuvieron el en poder durante poco más de un año hasta que las tropas de Bayraktar consiguieron deponer a Mustafa IV en beneficio de Mahmud II, quien continuaría con la línea de reformas instaurada por Selim III. Bayraktar se convirtió en gran visir y logró reclutar 5000 soldados del extinguido cuerpo de los nizam-i cedî́d que en 1809 sumaban el doble. El nuevo sultán consiguió ir debilitando las fuerzas y el apoyo popular a los jenízaros para poder así acabar con ellos. En 1826, aprovechando el descontento por una serie de derrotas en Grecia., los reunió en la plaza de Atmeydan en Estambul ordenando acto seguido su ejecución en masa. Este acto, conocido como The Auspicios Event, supuso en el resto de Europa el reconocimiento de los otomanos en integrase en la Modernidad, acabando con un ejército ineficaz e, incluso, anacrónico ${ }^{7}$. La caída de estos guerreros arrastró también a la de los derviches bektasi, una milicia de monjes seguidores de Haci Bektas que acompañaban a los jenízaros en sus campañas.

Mantanan, R. (ed), Histoire de l'Empire Ottoman, Paris, Fayard, 1989, pág. 426.

5 BADIA y LEBl. ICH, Domingo, Viajes por Africa y Asia, Barcelona, Olimpo, 1953, pág. 502. Primera edición en francés en Paris, 1814. En España, Valencia 1836, 3 vol.

Ib.

WhEATCROFT. Andrew, The Ottomans, Londres, Viking, 1993, dedica el capítulo 4: "The auspicius event»: the extirpation of the Janissaires pags. 84-137. 
En 1827, un año más tarde, España y Turquía firman un segundo tratado que permitirá el paso de los barcos españoles al mar Negro a través de los estrechos del Bósforo y los Dardanelos ${ }^{8}$. Este tratado y la Guerra de Independencia Helena (1821-29) volverá a atraer la atención española sobre la Cuestión de Oriente. La prueba de ello son dos textos: Descripción Geográfica, Política, Militar y Religiosa del Imperio Otomano por Vicente Roger Coma en 1827 y La Turquía Teatro de la Guerra Presente en 1828 de Fermín Caballero. Los dos se basan en fuentes anteriores, dedicando el primero bastante importancia al ya extinto cuerpo de los jenízaros ${ }^{9}$. Fermín Caballero si da noticias del fin de estas tropas en una sola página (origen, progresos y extinción de los jenizaros, pág 199) donde desarrolla el tema.

Los lectores españoles tuvieron más información sobre el Imperio Otomano en general y sus tropas en particular con la traducción de textos de literatura de viajeros, como es el caso del Viaje a Oriente de Lamartine, un autor francés bastante traducido en España ${ }^{10}$. Este viajero se solidarizó con la causa turca y su intento de ponerse a la altura de las demás potencias europeas. De esta manera recorrió el lugar de la masacre en 1832 describiendo los últimos días de Selim III y el final de los que le ajusticiaron, dos temas que analizará en obras posteriores. El resultado es un texto de literatura de viajeros con abundantes referencias a acontecimientos históricos vistos desde una perspectiva claramente romántica:

La plaza del Atmeydan aparecía ennegrecida, detrás de las blancas paredes del serrallo: ella me recordaba la acción más grande de este príncipe que fue la extinción de los jenizaros (...) Un oficial egipcio golpeó a un soldado turco, y los jenízaros derramaron sus marmitas: el sultán instruido y preparado para todo, se encontraba con uno de sus principales consejeros en uno de sus jardines sobre el Bósforo: acudió al momento al serrallo, y tomó el estandarte sagrado de Mahoma: el muphti y los ulemas, reunidos alrededor del estandarte, pronunciaron la abolición de los jenizaros. Las tropas regulares y los fieles musulmanes se armaron y reunieron a la voz del sultán,

\footnotetext{
8 DEl CantILlo, Alejandro, Tratados, convenios y declaraciones de paz y de comercio que han hecho con las potencias extranjeras los monarcas españoles de la casa de Borbón, desde el año de 1700 hasta el dia, Madrid, Alegria y Charlain, 1843.

9 PARTE SEGUNDA, Organización del Imperio Otomano: Milicia de los turcos.-Jenizaros pagados.-Modo de guerrear de los jenizaros y de toda la infantería turca.-Jenízaros sin pagar.-Spahis o caballeria turca pagada.-Zaims y Timaris o Timariots.-Topchis o artilleros.-Disciplina.-Campamentos.-Estandarte de Mahoma.-Marina.-Objeciones y respuestas relativas a la fuerza militar de los turcos y sus derrotas actuales.-Elevación y decadencia del Imperio Otomano.

10 Para tener una idea de la repercusión de la obra de este poeta, novelista, historiador y politólogo francés en la España del pasado siglo véase las págs. 531-532 del tomo 11 del Diccionario Enciclopédico Hispano Americano, Barcelona, Montaner y Simón, 1892.
} 
y este avanzó a caballo al frente de las tropas del serrallo. Los jenízaros, reunidos sobre el Atmeidan, le respetaron: él atravesó varias veces la amotinada muchedumbre, solo, a caballo y arrastrando la muerte; pero animado de ese valor extraordinario, que infunde una resolución definitiva: ese debió de ser o el último día de su vida, o el primero de su libertad y poder. Sordos a su voz los jenizaros, se negaron a reconocer a sus agas, y acudieron de todos los puntos de la capital en número de cuarentamil. Las tropas fieles al Sultán, los artilleros y los bostangis ocuparon las avenidas de las calles vecinas al Hipódromo: el Sultán mandó hacer fuego y los artilleros vacilaron: un oficial determinado, llamado Kara-Djehennem, corrió a uno de los cañones, disparó su pistola sobre el cebo de la pieza, y el tiro de metralla derribó a tierra los primeros grupos de los jenizaros: estos retroceden; el cañón hizo fuego en todas direcciones sobre la plaza, y el incendio consumió los cuarteles. Prisioneros en tan estrecho espacio perecieron a millares bajo las paredes desplomadas, y entre las llamas mismas; y la ejecución que comenzó desde luego, no acabó sino con el último de los jenízaros, ciento veinte mil hombres alistados en la capital solamente, fueron victimas del furor del pueblo y del Sultán, y las aguas del Bósforo arrastraban sus cadáveres al mar de Mármara: los demás fueron confinados al Asia Menor y perecieron en el camino ${ }^{11}$.

La Guerra de Independencia Helena (1821-29) apenas tuvo repercusión en una España cuya atención se centraba al otro lado del Atlántico, al ser esos mismos años cuando se producen la emancipación de gran parte de las colonias de ultramar. Habrá que esperar a la guerra de Crimea (1853-55) para que el interés se vuelque sobre la cuestión de Oriente. Este conflicto fue seguido de cerca por algunas de las revistas ilustradas de la época: "Tantas veces hemos tenido que escribir en nuestro MUSEO DE LAS FAMILIAS, especialmente en el año anterior al describir la gigantesca guerra de Oriente, el nombre de la Crimea, que creemos será grato a nuestros lectores una rápida descripción del teatro en donde se ha representado el último gran drama que ha tenido por actores a cinco grandes naciones, y por espectadores a la humanidad entera» ${ }^{12}$.

La razón del interés español es la presencia en el conflicto en el bando pro-otomano, compuesto de una primera expedición capitaneada por Juan Prim en el frente del Danubio y la posterior participación de dos oficiales de ingenieros, Tomás O'Ryan Vásquez y Andrés Villalón Echeberría, y varias

Lamartine, Viaje a Oriente, 1846, págs. 220-222. La edición original es de París, 1835 Esta obra tuvo en España al menos tres ediciones, la anteriormente citada es de Madrid. Hay una fechada en Córdoba en 1840 y el mismo texto con el nombre Viaje a la Palestina en Valencia en 1844. También trata este tema en Le Nouveau Voayage en Orient, Paris, 1851 y en Histoire de la Turquie, París, 1855, en ocho volúmenes donde el último está prácticamente dedicado al final de los jenizaros.

12 J.M.G. "La Crimea", Museo de las Familias, 1855, pág. 274 
fragatas españolas en la batallas de la península de Crimea. Hay que tener en cuenta que este conflicto atrajo a muchos soldados españoles, veteranos de Argelia y de las guerras carlistas, que formarían un contingente de 1.460 voluntarios en las tropas anglo-francesas ${ }^{13}$.

Si bien en esta guerra los otomanos quedan en un segundo plano tras la Rusia agresora, la armada británica y las tropas de Napoleón III, los observadores españoles no dejan de aportar datos sobre su estado y evolución. Las noticias sobre el ejército turco crean una imagen donde coexiste el pasado glorioso con el progreso: "En cuanto a las virtudes militares de la Turquía, fiel a su historia, es todavía un plantel de buenos soldados (...) Como artilleros, los turcos tienen un excelente golpe de vista: apuntan con precisión, exactitud y sangre fría. Como soldados de línea están perfectamente fogueados. Como ingenieros, sin grandes conocimientos adquiridos, tienen el instinto de la fortificación, del ataque y de la defensa de la plaza» ${ }^{14}$.

De todas las obras de literatura militar que se publicaron y tradujeron una de las más interesantes es la memoria de Prim, recientemente reeditada por el Ministerio de Defensa con una introducción a cargo de D. Manuel Espadas Burgos. Este autor señala la ambigüedad de las naciones que apoyaban a Turquía sobre el reconocimiento de la modernización de su ejército, a causa de la derrota contra los egipcios una década atrás. Lo cierto es que los otomanos contaban con los siguientes centros de formación: la Escuela Naval, la Escuela de Ingenieros Militares, la Escuela Militar de Medicina, la Escuela de Ciencias Militares ${ }^{15}$. Con todos estas instituciones se puede apreciar el proceso de reformas, Tanzimat, que tiene en el sucesor de Mahmut II, Abdül-Mecit (1839-61) un digno continuador de su obra.

Antes de pasar a la descripción de la campaña del Danubio el general Prim aporta toda una serie de datos sobre la composición de las tropas turcas, con un punto de partida que mantiene la desconfianza de que hayan realmente alcanzado la Modernidad en lo militar: «El principal elemento de todas las naciones, es el ejército: su más glorioso recuerdo a las guerras; y el orgullo de las generaciones los triunfos de los antepasados. La Turquía de hoy vive de lo que fue, y prolonga su existencia produciendo lo que no

\footnotetext{
3 Pando Despierto. Juan: «Españoles en Oriente, campañas del Danubio y Crimea", Revista de Historia Militar, año XXXI, n.ำ 62, págs. 113-115.

"Turquía y los turcos", Museo de las tamilias, 1855, pág. 201

Espadas BuRgos, Manuel, pág. XXXII de la introducción de Un Viaje Militar a Oriente, Juan Prim, M.ำ de Defensa. 1995, (1. 를 ed 1855).
} 
tiene" ${ }^{16}$. A continuación el general español traza un repaso del esplendor de los ejércitos otomanos donde la figura del sultán, llamando a la guerra a todos los fieles, constituía el factor de cohesión de las tropas. En este contexto y cayendo en el tópico de la literatura de viajeros, Prim vuelve a realzar la figura de los jenízaros y los derviches que les acompañaban como responsables de las glorias de antaño. Esta descripción de los antiguos ejércitos otomanos, no exenta de cierta nostalgia, y el mayor número de personas dedicadas al servicio de las armas son las razones de Prim a las palabras anteriormente citadas; aunque más adelante reconoce los progresos otomanos «El ejército turco no es, ni con mucho, lo que era en los años 28 y 29 . El soldado está más aguerrido y mucho más disciplinado " 17 . Prim, con el apoyo de varios cuadros de cifras, pasa un repaso a los diferentes cuerpos con sus respectivas instituciones llegando a esta conclusión:

El conjunto de las fuerzas militares en Turquía es el siguiente:

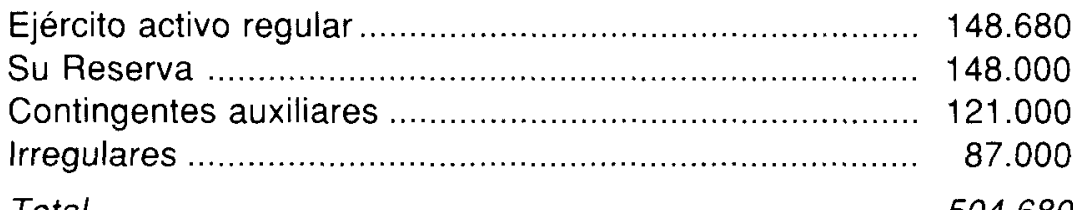

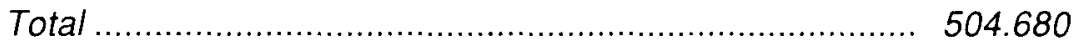

Sobre la marina vuelve a realizar una pequeña síntesis histórica desde la destrucción de la flota turca por los rusos en Çesme en 1770, la aportación del barón de Tott, las pérdidas en la guerra de independencia helénica o contra los egipcios liderados por Mehmed-Ali en 1840 para explicar el reducido número de navíos de guerra del Imperio Otomano:

Efectivos de flota:

2 Navíos de tres puentes de 130 a 120 cañones.

4 Idem de dos puentes de 90 a 74 cañones.

10 Fragatas de 60 a 40 cañones.

6 Corbetas de 26 a 22 cañones.

14 Bergantines de 20 a 12 cañones.

16 Goletas de 12 a 16 cañones.

16 Fragatas de vapor de 800 a 450 caballos.

12 Buques menores.

80 Total

lb., pág. 51.

1b. pág. 74. 
La derrota rusa de Sebastopol con la consiguiente victoria otomana supone una excepción de la presencia española en el escenario del Imperio Otomano. Pocos años más tarde, con la toma de Tetuán en 1860, la atención se centraría en el norte de Africa abandonando los territorios de la Cuestión de Oriente ${ }^{18}$. A pesar de ello el acercamiento hispano-otomano se mantuvo fletando nuevas expediciones como el caso de la fragata Arapiles en 1871. Si la memoria de la expedición de Aristizábal es un tratado sobre el Imperio Otomano a finales del siglo XVIII la de Juan de Dios de la Rada, aparecida entre 1876 y 1882 en tres volúmenes, lo es sobre el Mediterráneo oriental. Sobre el tema del presente artículo de la Rada tuvo acceso a estadísticas de 1867 que señalan que para entonces el ejército otomano, que desde Crimea no había vuelto a participar en ningún conflicto internacional, mantenía su línea de acercamiento hacia los modelos venidos del resto de Europa «Uno de los ramos de la administración turca en que más se han sentido las modernas reformas, es el ejército y la marina» ${ }^{19}$. Según los datos aportados por este autor en ese momento contaban con 80 regimientos de los cuales 36 eran de infantería, 24 de caballería, 10 de artillería, 2 de ingenieros y 8 de cuerpos destacados, lo cual daba un número de 100.496 hombres. De la Rada continúa con los 300.000 de la reserva y las tropas irregulares; aunque de estos no parece tener una buena impresión: "En caso de necesidad el ejército activo puede aumentarse con un número indefinido de tropas irregulares, cuyos voluntarios, conocidos con el nombre de bachi-bozuchs, con su turbulencia y su insubordinación, son más perjudiciales que útiles en los ejércitos tur$\cos { }^{20}$. Si se comparan las cifras de Prim se puede llegar a la conclusión de que Turquía mantenía un ejército similar, en previsión de nuevos ataques de los rusos.

Donde si se notan diferencias es en la marina otomana, destruida en 1854 junto a las costas de Sinop durante la guerra de Crimea. Siempre según datos de 1867 contaban con 163 buques, la mayor parte a vapor, 52 fragatas de las cuales cinco eran acorazadas, 19 navíos de vela y 92

\footnotetext{
18 Sobre este tema en general uno de los pocos estudios que existen son obra de Victor MORlal.es LeZCANO: Africanismo y Orientalismo Español en el siglo xix. Madrid UNED, Aula Abierta n. ${ }^{\circ} 41,1989$ y España y La Cuestión de Oriente, Madrid, Biblioteca Diplomática Española, 1992. Este autor opina que en España no hubo un Orientalismo propiamente dicho sino un Africanismo. centrado en los territorios magrebies. Si bien la abundancia de textos sobre los protectorados es. pañoles en el norte de Africa superan con mucho los que tratan sobre el Imperio Otomano, un más detallado estudio sobre todos los documentos existentes permite realizar un análisis sobre la opinión española de la Cuestión de Oriente.

De la Rada y Delgado, Juan de Dios, Viaje a Oriente de la fragata de guerra Arapiles. Barcelona, S.L., 1882, 2. vol, pág. 234
}

lb. pág. 235 
barcos menores. Estas embarcaciones estaban bajo el mando de un almirante, cinco contra-almirantes, tres brigadieres y ocho coroneles o capitanes de navío; contando con 40.000 soldados y marineros y 2.370 cañones.

Otro aspecto que ha cambiado desde la guerra de Crimea es el del uniforme. Prim lo describía como un fez, el emblemático gorro rojo turco impuesto por Mahmut II en sus reformas en la indumentaria, y un uniforme azul oscuro con vivos encarnados para toda la infantería. El de la caballería y la artillería varía siendo el pantalón el mismo para todos. De la Rada destaca el pantalón rojo, levita abrochada fez y fornituras.

Otro interesante documento es el de otro tripulante de la fragata Arapiles, Vicente Moreno de la Tejera. A diferencia de de la Rada él sí era militar aunque, paradójicamente, escribiera un libro más cercano a la literatura de viajeros que a la memoria científica de de la Rada. El Diario de un Viaje a Oriente es, como su nombre indica, las memorias de este autor que pretenden llenar el vacío existente en las letras hispánicas sobre el tema. Si la persona de de la Rada no aparece en el texto Vicente Moreno de la Tejera es el protagonista absoluto de su relato, cuyas opiniones no están basadas en otros textos o datos sino en su percepción personal. Una de las anécdotas más interesantes, que no habría tenido lugar en la memoria de su compañero, es la subida a bordo de un oficial turco al pasar el estrecho de los Dardanelos. Moreno de la Tejera narra como el capellán de la Arapiles le ofreció un bollo de manteca de cerdo y un vaso de vino siendo aceptados al instante. Si bien este gesto de desafiar dos prohibiciones del Islam, la carne de cerdo y el alcohol, demuestran que el oficial otomano podia prescindir de su credo para adaptarse a otras costumbres, Moreno señala que el vulgo sigue siendo fanático. Esta actitud, a caballo entre lo que se percibe y las idea preconcebida sobre el pueblo turco, es la que se va manteniendo en las mentes de los observadores extranjeros. El esfuerzo de los otomanos de alcanzar la Modernidad suele ser puesto en duda, entre otras cosas por el hecho de mantener una serie de territorios sobre los cuales han puesto los ojos los apetitos colonialistas de la época.

A pesar de la derrota de Crimea los objetivos de la política expansionista rusa se habían ido manteniendo a través de la difusión de una corriente nacionalista, el Paneslavismo, en la cual se pretende unificar a todos los pueblos eslavos bajo el amparo de la figura del zar. Paralelamente en el Imperio Otomano las reformas del Tanzimat alcanzan el 1876 uno de sus objetivos con la proclamación de la Primera Epoca Constitucional, Birinci Mesrutiyet, en la cual todos los súbditos otomanos iban a ser considerados iguales ante la ley. Si bien las reformas turcas apenas tienen 
repercusión al otro extremo del Mediterráneo no sucede lo mismo con la política rusa. Su evolución fue seguida bastante de cerca en España por un grupo de intelectuales cercanos a La Ilustración Española y Americana. Emilio Castelar en 1876 publicó La Cuestión de Oriente donde miraba con suspicacia la política rusa, basada en la protección a los cristianos ortodoxos otomanos en general y el apoyo a los pueblos eslavos en particular, es decir, un planteamiento muy similar al de 1853 en que, por una serie de rivalidades entre los cristianos latinos y los ortodoxos, estallaría la guerra de Crimea.

Un año después de la aparición del libro de Castelar Enrique Dupuy de Lôme con Los Eslavos y Turquía se muestra partidario de la política rusa. Dupuy, desde una perspectiva eurocentrista, considera la presencia de los otomanos en Europa como un freno para los pueblos eslavos que les impide alcanzar el papel que les corresponde: "Su raza debe llenar en el mundo una misión grande y sublime que consiste en volver a convertir en Europa en unión con los pueblos griegos lo que ahora es Asia, a pesar de estar en nuestro continente» ${ }^{21}$.

Tal y como había previsto Castelar la agresión rusa en los Balcanes no se hizo esperar y en junio de 1877 tropas de esta nación se dirigieron hacia el Danubio, iniciándose así la guerra ruso-turca de 1877-78. AbdülHamid, el nuevo sultán, al principio de la contienda tomando el estandarte de Mahoma y arengando a sus tropas proclamó la Guerra Santa, finalizando de esta manera con la Primera Epoca Constitucional ${ }^{22}$. Esta medida fue interpretada en el resto de Europa como una vuelta a los valores religiosos musulmanes, considerados como un freno para el progreso y aislándole de sus antiguos aliados en Crimea. Los lectores españoles e hispanoamericanos encontraron abundante información sobre el conflicto en las páginas de La llustración Española y Americana que contó con un corresponsal de guerra, José Luis Pellicer, cuyos grabados y "Cartas desde la Guerra", reprodujo, y, las opiniones de Emilio Castelar, Manuel Becerra y Enrique Dupuy de Lôme, encargado de seguir el conflicto titulado "La Guerra de Oriente" a lo largo de veinte entregas. Sus testimonios sirven para realizar un análisis de la guerra desde los primeros días de la contienda: "Salen palabras amenazadoras del parlamento inglés; en el Foreing Office se escriben notas enérgicas; de los puertos y arsenales

21 Dupur de LOME. Enrique, Los Eslavos y Turquia, Madrid, La llustración Española y Americana, pág. 75

${ }_{22}$ Sobre este conflicto véase las págs. 182-184 de StandFORO \& EzEL SHAw, History of the Ottoman Empire and Modern Turkey, vol II: Reform, Revolution and Republic. The Rise of Modern Turkey, Cambridge University Press, 1977. 
nos vienen rumores sombríos. Alemania tiene un silencio de esfinge; Francia tiene que olvidar que sus soldados han estado en Alma, en Inkermann y en Navarino. En Austria los croatas reciben al Archiduque Alberto al son del himno nacional ruso, y los húngaros vitorean los sofas y les llaman hermanos 23 .

La situación internacional hacía temer una guerra similar a la de Crimea con la participación de las principales potencias europeas; sin embargo, la crisis económica que se cierne sobre buena parte de Europa y la situación política internacional era bien distinta. El fin del II Imperio Francés con la batalla de Sedán en 1870, los sucesos de la Comuna y las crisis económica que supuso la pérdida de Alsacia y Lorena no permitían embarcarse en otro conflicto armado. Alemania, una vez finalizada su unificación, se mostraba expectante ante su peligroso vecino y algo parecido sucedía en el Imperio Austro-Húngaro, cuyas miras también estaban en los Balcanes. Inglaterra fue la única en condenar la agresión ya que la expansión rusa por Asia central les situaba muy cerca de sus posesiones en la India.

La España los pocos intelectuales que se preocuparon estaban divididos entre Castelar y Becerra, de ideología republicana, que miraban con susceptibilidad la ofensiva rusa y la postura contraria de Dupuy que vuelve a recuperar la imagen de las tropas turcas de antaño en una guerra donde los turcos representan la barbarie y los rusos la civilización: "Las flotas otomanas llevan la destrucción y la muerte por las costas de Crimea; en las gargantas del Caúcaso chocan razas diferentes, y en nombre del Tsar se establecen funcionarios civiles en las ciudades armenias que se van apoderando" ${ }^{24}$. Esta toma de contacto es la que predominará a los largo de las veinte entregas de "La Guerra en Oriente", donde la información sobre las operaciones de las tropas rusas es superior a la de sus contrincantes, tanto en los detalles de las operaciones como en la de sus protagonistas. A modo de ejemplo valga la siguiente cita que supone la primera aparición en la crónica del ejército otomano en un acontecimiento concreto:

Un día el Lufti Djelil, monitor de torres armado de cinco piezas de artillería, dos de nueve pulgadas en el torreón de delante, dos de siete en el de atrás y un cañón Amstrong de cuarenta libras en la proa, mandado por Nebjib bey, con doscientos hombres de tripulación, se acerca valientemente a Braila y empieza el combate con las baterías rusas. Un teniente de artillería

23 Dupuy DE LOME, Enrique, "Crónica de la Guerra de Oriente, I", Madrid, La Ilustración Española y Americana, 1877, n. XIX, pág. 333.

$24 \mathrm{lb}$. 
ruso, muy joven, imberbe, casi un niño llamado Somouilo, apunta una pieza en la batería núm 1; cae la bomba en la cubierta del monitor, que no estaba blindada, o entra por la chimenea, y produce una explosión horrible. El barco se va a pique, los cuerpos mutilados de todos sus tripulantes son arrojados por los aires, y caen unos destrozados en tierra a gran distancia de la orilla, otros en el río que los lleva a descansar al mar Negro, y el Gran Duque Nicolás puede enviar a su hermano como trofeo un estandarte turco ${ }^{25}$.

Según el mismo Dupuy las poderosas armas modernas están revolucionando el desarrollo de los combates. La muestra más evidente es la utilización de torpedos, inventados en 1805 pero que no llegaron a utilizarse con éxito hasta la Guerra de Secesión de Estados Unidos (1861-65). Como la Guerra Franco-alemana de 1870-71 no había contado con combates navales importantes los europeos no eran conscientes del alcance de las nuevas armas: "Los torpedos no son aparatos de grandes dimensiones, ni asustan a primera vista. Los que han colocado los rusos en los cauces en el Danubio son cilíndricos, de 64 centímetros de altura y $50 \mathrm{de}$ base, terminados en punta. Una mezcla de dinamita y otras materias les da la fuerza explosiva que produce la catástrofe " ${ }^{26}$. Inglaterra fue la más preocupada por su utilización; ya que basaba gran parte de sus fuerzas en la Armada Británica, cuyas formidables fortalezas flotantes podian irse a pique con facilidad.

Si bien como dije antes las noticias sobre los rusos sobrepasan a las de los turcos Dupuy analiza su ejército compuesto de 230 batallones de 750 hombres como media, 72 escuadrones de 100 jinetes, 8.000 entre artilleros e ingenieros y 300 cañones los cuales formaban un total de 200.000 hombres y 7.200 caballos. Alejando II, por su parte, había conseguido movilizar a 218.000 soldados y se había comprometido a que Rusia no tocaría Egipto o el canal de Suez, ni se quedaría con Estambul ${ }^{27}$. De esta manera había conseguido acallar las protestas británicas y hacer de la guerra un conflicto regional.

Los rusos tenían abiertos dos frentes: el del Danubio y el del este de Anatolia donde tras haber tomado Ardahan (18 de mayo 1877), y Beyazit (20 de junio) avanzaban hacia Erzurum. Muhtar pachá ${ }^{28}$ les intentaba detener con el $4 .{ }^{\circ}$ cuerpo del ejército aumentado con contingentes de la

Ib, n. $\cong X X \mid$, pág. 366.

lb.

Ib, n.XXII, pág. 391

Las memorias de este general turco (1839-1919) presente en buena parte de las guerras de la segunda mitad del siglo pasado han sido recientemente publicadas con el título de Anilar, (Recuerdos), Estambul, Tarih Vakti, 1996, 2 vol. 
capital otomana, de Siria y de tropas irregulares kurdas y circasianos que sumaban 70.000 hombres, 180 cañones y 5.000 caballos. El ejército ruso poseía el doble de infantería y de cañones, y, cuatro o cinco veces más de caballería ${ }^{29}$. La atención se centró en la defensa de Kars, donde las tropas de Muhtar pachá consiguieron detener a los rusos hasta el 14 de Noviembre. Una de las causas del éxito otomano en la defensa de Kars era la ciudadela que domina esta ciudad y los doce fuertes destacados a lo largo del río sobre los cuales Dupuy da bastante información en el n. 9 VI de "Crónica de la Guerra de Oriente" con un plano de la ciudad y sus fortificaciones.

Este frente sería abandonado posteriormente concentrando los esfuerzos en el abierto a lo largo del Danubio, especialmente en la defensa otomana de Plevna y el paso de Sivka, popularizados por la prensa británica simpatizante con el bando turco ${ }^{30}$. En el caso de Plevna Dupuy informaba a los lectores de Ilustración Española y Americana de las 10.000 bajas rusas analizando este enfrentamiento: «La batalla de Plewna ha perdido su importancia porque los turcos no han sabido sacar partido de ella. Sin embargo, es muy digna de ser tenida en cuenta porque nos ha demostrado la ineficacia del plan de campaña ruso y sus muchos defectos" ${ }^{31}$.

Con la entrada de Grecia y Serbia en la guerra la balanza se orientó definitivamente hacia el bando ruso, aislando a las tropas de Albania. El 10 de Diciembre Osman pachá, tras cinco meses de asedio, entregó la plaza de Plevna y mes y medio más tarde los rusos llegaban a Edirne donde se firmó el armisticio el 21 de enero de 1878. Las paces de Berlín y el tratado de San Estéfano de julio de ese mismo año cambian el mapa de los Balcanes marcando la retirada de los otomanos de Europa. Se reconoce la independencia de Rumania, Serbia, Montenegro y parte de Bulgaria. Austria-Hungría obtienen la administración de Bosnia Herzegovina y Rusia parte de Anatolia oriental. Desde España otra de las publicaciones que estuvo pendiente de los cambios en el panorama político internacional es el Boletín de la Real Sociedad Geográfica de Madrid que, desde su fundación en 1876, raro es ejemplar que no aporta información sobre los territorios otomanos. Ferreiro en "Turquía y el tratado de Berlín» se solidariza con la causa eslava viendo un cierto paralelismo entre su situación con los otomanos y los cristianos de la península lbérica durante el supuesto "yugo" musulmán. Esta opinión hay que entenderla en el marco de

Dupuy, O.C., n..$^{\circ}$ XIII, pág. 407.

SHaw \& SHAW, c.c, pág. 184

Dupuy, o.c., n. ${ }^{\circ} \mathrm{XX}$, pág. 95. 
la Restauración, en la cual España vivía, tras la Primera República, una revitalización de los valores religiosos.

Otra publicación de la misma época interesada en la Cuestión de Oriente fue la Revista Contemporánea donde Francisco Barado y Font analiza las innovaciones aplicadas a las dos últimas guerras: la Franco-Prusiana de 1871 y la Ruso-Turca que acababa de finalizar. Se trata de un interesante documento sobre este todavía poco conocido tema que es la opinión española sobre los conflictos internacionales durante la segunda mitad del pasado siglo. Según Francisco Barado a partir de estos conflictos se podía afirmar que preponderaba la inteligencia sobre la fuerza. Los adelantos tecnológicos como la aereoestación, el telégrafo, la telefonía y los rápidos medios de transporte habían revolucionado las artes militantes, tal y como afirmaba Dupuy con el tema de los torpedos. Sobre los turcos destaca el éxito de las tropas otomanas en sus fortificaciones que habían ocasionado a sus enemigos, dando a la defensiva un valor importante al poder servirse de los nuevos fusiles. Los rusos practicaban el fuego a corta distancia sirviéndose en bastantes casos de la bayoneta, mientras los turcos hacían fuego a discreción y a todas las distancias. En este contexto el fusil de carga rápida modificó por completo las formaciones de combate y el empleo de las tres armas. Los estrategas habian comprendido la importancia del choque en estas nuevas batallas así como la de los movimientos envolventes y así Francisco Barado concluye su artículo de la siguiente manera: «todo lo que ha sido dado a la ciencia y a la inteligencia, ha disminuido la individualidad del combatiente, esa individualidad que en el mundo antiguo fue tan grande" ${ }^{32}$.

A partir de esta batalla y hasta los primeros años de este siglo Turquía vivió un periodo de calma durante el sultanato de Abdül-Hamid que, al igual que en otros imperios policulturales como Rusia o Austria-Hungría, manejaba con mano de hierro sus territorios. A pesar de las críticas que este soberano recibía lo cierto es que los otomanos vivieron un período de prosperidad. Así lo demuestra el Diccionario Enciclopédico Hispano Americano (1887-1899) que contaba con Julián Suárez Inclán para el arte Militar y la Justicia Militar. Como llevaba sucediendo a lo largo de la historia este texto concede bastante importancia al ejército otomano basado en datos de 1892:

La desgraciada guerra de 1877-78 indujo al gobierno otomano a confiar la reorganización del ejército a oficiales alemanes, llevándose a cabo la reforma

\footnotetext{
32 Barado y Font, Francisco, “Las Batallas Modernas", Revista Contemporánea, tomo XVI (jul-ag 1878), pág. 447.
} 
bajo el siguiente plan en la distribución de las fuerzas: dos regimientos de zuavos, 56 de infantería y uno de infantería montada, que en total componen 246 batallones; un regimiento de guardias y 37 de caballería con 190 escuadrones; ocho regimientos de artillería de campaña, 12 baterias montadas, dos de montaña y ocho regimientos de artilleria de campaña: total 208 baterias; cuatro regimientos de artilleria de plaza y cuatro batallones aislados; dos regimientos de obreros de artillería y dos batallones de escuela práctica; tres regimientos de ingenieros, cuatro batallones y dos compañías sueltas de zapadores; uno de telegrafistas; un regimiento de bomberos y 21 compañias de transportes. El ejército territorial se compone de 96 regimientos y la reserva de 48 . El total de las fuerzas activas (nizam) es de 12.000 jefes y oficiales y 170.000 individuos de tropa, con 30.000 caballos, 1.248 cañones de campaña y 2.300 de plaza, divididas en 7 ordus o cuerpos de ejército al mando del muchir o general en jefe, cuyos cuarteles generales son: Constantinopla, Adrinópolis y Monastir en Europa; y Erzingan, Bagdad, Damasco y Sana, en Asia. En 1892 la marina de guerra constaba de tres acorazados de casamatas, dos cruceros de baterias blindadas, siete corbetas acorazadas, un monitor acorazado, un cañonero acorazado para navegación por mar y dos para navegación fluvial, seis corbetas, tres torpederos, 12 lanchas torpederas de primera clase y seis de segunda, 11 cañoneros y avisos, tres yats imperiales, dos torpederos submarinos sistema Nordenflendt, cuatro embarcaciones y gran número de vapores y pequeñas embarcaciones no clasificadas. El personal de la escuadra es de siete vicealmirantes, 11 contraalmirantes, 130 capitanes de navío, 25 de fragata, 300 capitanes tenientes, 250 tenientes, 200 alféreces de navio, 30.000 marineros y 9.650 soldados: total 40.572 hombres $^{33}$.

Otra fuente de información sobre el Imperio otomano que hasta ahora no he tratado son los diplomáticos españoles destinados en los consulados y legaciones, especialmente si sus despachos transcendían de los ministerios y se publicaban como libros de memorias. Ese es el caso de $A$ Orillas del Bósforo de Antonio de Zayas y Beaumont, también conocido como el duque de Amalfi, que obtuvo un cierto reconocimiento como literato ${ }^{34}$. Zayas ocupó la plaza de secretario de tercera entre el 1 de enero de 1897 y el 30 de julio de 1897, en un momento en que las masacres de armenios habían estremecido a la opinión pública internacional. La cuestión armenia y la de Creta son analizadas por este autor desde el punto de

33 DEHA, 0.C., tomo 21, año 1897, pág. 786.

34 Sobre este autor y su papel como mediador entre España y el Imperio Otomano véase mi articulo "Antonio de Zayas y los sefardies otornanos", Raíces (Madrid,Sefarat ed), n. " 32 (otoño 97) págs. 61-64. Aunque hoy en día haya pasado casi al olvido fue una figura menor de la época tanto como poeta como por el hecho de ser traductor de los parnasianos franceses. Su obra ha sido tratada por Beatriz HeRRÁnz AnGULO: "1903: Soledades de Antonio Machado y Paisajes de Antonio de Zayas: dos visiones andaluzas del Modernismo Hispánico", Antonio Machado Hoy, actas del congreso internacional conmemorativo del cincuentenario de la muerte de Antonio Machado, Sevilla, tomo III, págs. 67-79. 
vista de la guerra entre miembros de diferentes religiones en la cual los cristianos continúan representando la civilización y los turcos la barbarie. La opinión de Zayas sobre la actuación de la flota internacional en Creta es criticada «Por la conducta de los almirantes que aparecieron realmente como protectores de los musulmanes refugiados al amparo de los batallones de desembarco y como enemigos de los insurrectos cristianos a quienes cañoneaban con más o menos vigor repetidas veces" ${ }^{35}$. Si bien como habia pasado en la Guerra Ruso-Turca de 1877-78 las potencias europeas se mantuvieron al margen de lo que en principio era un insurrección interna la postura de Antonio de Zayas se mantiene en la defendida por Carlos V y Felipe II en la lucha contra el turco. Este posicionamiento puede ser considerado como representativo de los sectores más reaccionarios de la población española que miraban con suspicacia todo aquello que se saliera de los moldes impuestos por los Reyes Católicos y sus sucesores los Austrias.

Volviendo a la Cuestión de Creta, el desembarco de un contingente de tropas helénicas lideradas por el coronel Vassos transformó este conflicto interno tal y como cuenta el propio Zayas: "originó las primeras incursiones en los dominios otomanos y la concentración de los ejércitos turco y helénico en la frontera de Tesalia» ${ }^{36}$. Las tropas otomanas con consejeros alemanes y ya plenamente recuperadas de la derrota anterior consiguieron fácilmente la victoria, logrando este triunfo incrementar el prestigio del sultán y su ejército. Zayas analiza la contienda y la derrota de «un mal armado ejército de 80.000 hombres" ${ }^{37}$, restando mérito a las tropas otomano: "No hubo, en efecto, gran necesidad de desplegar grandes talentos estratégicos para humillar a un adversario que no presentó ni un instante la cara; y que si ha de tenerse por veraz el testimonio técnico de los agregados militares europeos que asistieron a la campaña, bien puede afirmarse que como hubiesen los griegos demostrado mayor aliento y disciplina, no hubiera sido tan menguada su suerte, porque los planes de Edem Bajá, General en Jefe de las tropas otomanas, no podían ser más absurdos» ${ }^{38}$.

Si bien desde la guerra de Crimea la mayoría de los observadores españoles se han ido posicionando en contra de los otomanos, Vicente Blasco Ibáñez supone un punto de vista diferente ${ }^{39}$. Así lo afirma justo antes

\footnotetext{
De Zayas y Beaumont, Antonio, A Orillas del Bósforo, Madrid, Juan Puello, 1912, pág. 398. lb. pág. 402 .

Ib. pág. 403 .

Ib.

Sobre este tema véase mi artículo “Blasco Ibáñez en Estambul», Letras de Deusto, julioseptiembre 1997, Bilbao, Universidad de Deusto.
} 
de llegar en tren a Estambul en 1907: "Yo soy de los que aman a Turquía y no se indignan por su prejuicio de raza o religión, de que este pueblo bueno y sufrido viva todavía en Europa» ${ }^{40}$. Unas líneas más adelante afirma que él ama al turco como lo han amado todos los escritores y artistas que lo vieron de cerca. Este planteamiento, muy similar al de Lamartine en 1832 , indica la existencia de las dos posturas existentes a la hora de crear la imagen de este pueblo: la recopilación de datos sin desplazarse a Turquía, y, la toma de contacto directo con ellos. Blasco lbáñez encarna la segunda produciendo una nueva imagen de los turcos. Las crónicas de este viaje fueron difundidas en El Liberal de Madrid, La Nación de Buenos Aires y El Imparcial de Méjico, antes de publicar Oriente en la editorial Senpere de Valencia en 1907. Hay que tener en cuenta que la Literatura de Viajeros es un elemento clave a la hora de dar a conocer la situación de un determinado pueblo o país, sobre todo si vienen firmadas por autores de la talla de Lamartine o Blasco Ibáñez.

Oriente es una obra que encaja bastante en el Modernismo hispánico, una corriente literaria donde abundan los viajes a países exóticos, el cosmopolitismo y las descripciones llenas de sensaciones como colores, brillos, sonidos, etc. Estambul tanto por su entorno geográfico, por su historia y por ser todavía la capital de un imperio policultural se convierte en un destino de peregrinación de viajeros. Uno de los aspectos que atraen su atención es la indumentaria de los militares que se cruzan en su camino, destacando de todos ellos el fez que les caracteriza, los uniformes de la tropa de estilo alemán y "Los oficiales, con sus insignias a la inglesa, enguantados de blanco, calzados de charol y el sable bajo el brazo" ${ }^{41}$. El novelista valenciano hace especial incapié en la descripción de ejército otomano durante el selamlik, la visita que realizaba el sultán a la mezquita de Hamidiye los viernes. Este acontecimiento congregaba al cuerpo diplomático y estaba precedido de un desfile militar. Blasco Ibáñez, utilizando los recursos estilísticos del Modernismo, traza un retrato del evento donde sale a relucir su capacidad para plasmar en papel todas las sensaciones que el desfile le produce:

Desfilan al son de estrepitosas bandas de bárbara marcialidad los regimientos de línea, vestidos de oscuro azul, llevando al frente a sus jefes, montados en pequeños caballos turcos, que aún parecen más diminutos bajo la obesidad de sus jinetes. Los batallones árabes se distinguen, en esta

¿o Blasco lbañez, Vicente, Oriente, Madrid, Aguilar, Obras Completas de Vicente Blasco Ibáñez, 1987 , tomo II, pág. 46

41 lb. pág. 54. 
aglomeración de cabezas rojas, por sus turbantes verdes, color religioso exaltado por el Profeta. Los albaneses, vestidos de blanco, a la zuava, forman en la puerta de palacio como tropa de preferencia, encargada de la guardia del sultán. Llegan los marinos de la escuadra, con sus oficiales a caballo: unos marinos de altas botas, que llevan al cinto por toda arma el ancho sable de abordaje. Al pie de la colina de Orto Keni ondean las rojas banderolas de los lanceros. Los regimientos de caballería tienen bandas de música, y se ve a los trombones, enroscados al cuerpo de los jinetes, como enormes serpientes de metal, saltar bruscamente a impulsos de los botes de los caballos, ocultos tras los pliegues del terreno.

El aspecto imponente de estas tropas se debe a la edad de los soldados. El ejército turco es un ejército duro. No se ven en sus filas muchachos barbilampiños y a medio formar, como en los ejércitos de Europa. El soldado turco es un hombre de veinticinco a treinta años; macizo, bigotudo, en todo el esplendor de su desarrollo. Unase a esto la fe ciega del mahometano, ese fervor religioso que inspira respeto por su ingenuidad aún a los más escépticos, y se comprenderá lo que es una masa de siete u ocho mil soldados otomanos. Después de verlos, nada puede asombrar de cuanto se diga sobre su resistencia ante el enemigo y su fiera conformidad ante la muerte. Se lo imagina uno mal dirigido en los campos de batalla y dejándose matar sin retroceder un paso. Pero volviendo la espalda no hay quien se lo figure.

Al detenerse y extender sus filas a lo largo del camino, descansan sus fusiles en tierra con un golpe seco y uniforme, y quedan inmóviles, con una inamovilidad que parece un sueño ${ }^{42}$.

Aunque el texto de Blasco Ibáñez carece de la información de otras obras anteriormente analizadas puede ser considerado un complemento a la imagen creada por las enciclopedias y los comentaristas de temas bélicos. Se trata fundamentalmente de la aportación a las letras hispánicas de un documento de literatura de viajeros por el Imperio Otomano, poco frecuente en nuestros textos. El carácter exótico de la crónica se mueve entre la percepción y todas las ideas sobre los turcos que precedieron al viaje, por eso son frecuentes las referencias al pasado o a la religión musulmana. Una vez más el conflicto ante el hecho de si los turcos han alcanzado la Modernidad o no se plantea a los lectores. Blasco lbáñez resuelve esta cuestión con la descripción de un militar, un joven teniente de navío con quien coincide en el barrio de Pera y en un oficio religioso musulmán, que adquiere en Oriente un valor simbólico definitivo: "Aquel marino era la personificación de la Turquía europea, que se apropia de inventos modernos, copia la organización alemana, habla todos los idiomas

${ }_{42}$ Ib., págs. 63-64. Sobre el selamlik véase por Paul FESCH, Constantinople aux derniers jours d'Abdul-Hamid, Paris, Librería de Ciencias Políticas y Sociales, 1907, el capítulo XXII (págs. 123-152): Le selamlik de l'Homrne malade. 
de los pueblos civilizados y adopta las modas de París..., pero guardando bajo su exterior su alma asiática» ${ }^{43}$.

La opinión de Blasco lbáñez sintetiza buena parte de lo hasta ahora expuesto: el intento de alcanzar la Modernidad adaptándose a las formas venidas del resto de Europa y su reconocimiento, sustentado en el ejército aparecido tras el exterminio de los jenízaros. Bajo los uniformes y el servicio a las armas subyace de una manera omnipresente la religión musulmana o lo que llama Vicente Blasco Ibáñez el alma asiática, dos aspectos que para los observadores españoles pueden ser considerados como una forma de enriquecer Europa, tal es el caso del novelista valenciano, o, para todo lo contrario, sometiéndola al despotismo y a la barbarie. Las opiniones que he ido presentando varian a lo largo de la historia, paralelos a unos intereses que salvo en Crimea fueron mucho más hipotéticos que reales. A pesar de la poca repercusión los documentos expuestos sirven para trazar la imagen del Imperio Otomano, personalificada en sus ejércitos, en la todavía poco conocida política externa española durante el siglo pasado.

\section{BIBLIOGRAFÍA}

ARRUE, Francisco: Guerras Contemporáneas. Estudios de Arte Militar. La guerra de Crimea. Madrid, 1889

BecerRA, Manuel: “Complicaciones de Oriente", Madrid: La llustración Española y Americana, $1878\left(1 .^{9}\right.$ semestre) págs.: 127-30, 146, 158, 172, 243-246, 319-322.

BusCHING: El Imperio de Osmán o la Turquia Europea. Madrid: Imprenta Real, 1785

Castelar, Emilio: La cuestión de Oriente. Madrid: Oficinas de la llustración Española y Americana, 1876.

COLAS, B.C: La Turquía desde la fundación de la casa de los seleúcidas hasta nuestros dias. Madrid, Aquiles Ronchi, 1866. Traducción de F.Climent y J. Bisso.

CONRoTte, Manuel: España y los paises musulmanes durante el ministerio de Floridablanca. Madrid: Patronato de Huérfanos de la Administración Militar, 1909.

Der Alluierten Streitkräfte, General Einem: Guerra de Oriente y expedición a Crimea: dirigida al gobierno de S.M.I Napoleón III por un general de los ejércitos aliados. Barcelona: Narciso Ramirez, 1855.

DUPONCHEL : Historias de Grecia e Italia desde los tiempos mas remotos hasta 1840. Barcelona: Brusi, 1844.

LAPORTE: El Viajero Universal o Noticia del Mundo Antiguo y Nuevo, obra compuesta en francés por Mr. de Laporte y traducida al castellano, corregido el original, e ilustrado con notas por D.P.E.P. Madrid: Imprenta Real, 1795, 24 Tomos.

Martinez del Romero, A: Historia Universal Antigua y Moderna Formada principalmente con las obras de los celebres escritores el Conde de Segur, Anquetil y Lesage y con presencia de las escritas Millot, Muller, Chateaubriand, Bossuet, Thiers, Guizot, Guay, Michelet, Robertson, Nodier, Montesquieu, Rollin, Mariana, Miñana, Solis, Torerno, Marliani, Michael etc . Madrid, 1842-45.

${ }^{43}$ Ib. pág. 73 . 
Mapa de la Turquía Asiática (escala 1/2.850.000) y Mapa de la Turquia Europea (escala 1/1.000.000)Publicado por el Depósito de la Guerra con arreglo al formado por el E.M. austriaco, 1877.

O'RYAN y VAzQuez, Tomás: La guerra de Oriente (1854-1856),conferencias dadas en el Centro del Ejército y de la Armada por el teniente General D. Tomás O'Ryan y Vásquez. Madrid: Imprenta del Memorial de Ingenieros, 1886.

- Memoria sobre el viaje militar a la Crimea, presentada por los oficiales del cuerpo de ingenieros nombrados en 1855 para seguir y estudiar las operaciones de la guerra entre Rusia las potencias occidentales, Francia e Inglaterra auxiliando a la Turquía. Madrid: Imprenta del Memorial de Ingenieros, 1858.

CHAKıB, Benafri: Las relaciones entre España, el imperio Otomano y las regencias berberiscas en el siglo XVIII (1759-1792), Tesis doctoral, Departamento de H. ${ }^{3}$ Moderna, Facultad de Geografía e H. ${ }^{a}$ Universidad Complutense de Madrid, 1994.

DJAIT, Hichem: Europa y el Islam. Madrid: Libertarias, 1990.

Garcia-Romeral Pérez, Carlos: Bio-Bibliografía de Viajeros Españoles (Siglo XIX). Madrid: Ollero \& Ramos, 1995.

InCIYAN, P: XVIII Asïrda Istanbul (Estambul en el sigio XVIII). Estambul: Baha Matbaasï, 1976.

Jover Zamora, José María: "La percepción española de los conflictos europeos : notas históricas para su entendimiento" La Revista de Occidente. Madrid, feb. 1986.

LITVAK, Lily: El Ajedrez de Estrellas, crónica de los viajeros españoles en el siglo xix por paises exóticos(1800-1913). Barcelona: Laila, 1986.

MANSEL, Philip: Sultans in Splendour, The Last Years ot the Ottoman World. Londres: André Deutsch Limited, 1988.

MAS, Albert: Les turcs dans la littérature espagnole du Siecle D'Or. París: (NRS), 1967.

D'OHsson Mouradjea, M.: Tableau Général de l'Empire Othoman. París, 1787.

Osmanli Askeri Teskilât ve Kiyafetleri 1876-1908, Ottoman Military Organization and Uniforms. Estambul: Askeri Müse ve Kültür Sitesi Komuntanlïgï Yayïnlarï, 1896.

TOTT, Baron de: Memoires du Baron de Tott sur les turcs et les tartares. Amsterdan, 1785.

YAPP, M.E.: The making of the modern Near East 1792-1923. Londres: Longman, 1989. 